\title{
OS LUGARES TURÍSTICOS: TERRITÓRIOS DO FENÔMENO TURÍSTICO
}

\author{
Aguinaldo CÉSAR FratuCCI*
}

Fenômeno típico da sociedade capitalista pós-revolução industrial, o turismo apresenta imbricações espaciais e territoriais diversificadas e passíveis de análises várias, conforme a escala de observação proposta. Fruto de atividades e práticas sociais diretamente relacionadas ao movimento e ao deslocamento espacial (NICOLÀS, 1996; MOESCH, 1998) de pessoas e de informações, na sua essência esse fenômeno produz e consome espaços (RODRIGUES, 1997, 1996; NICOLÀS, 1996; LUCHIARI, 1998) e, por consequiência, territorialidades e territórios.

O turismo manifesta-se através de diversas formas, modalidades e escalas dentro de um mesmo território. Está subordinado tanto às ações da iniciativa privada quanto do Estado e até mesmo das pequenas comunidades organizadas; todo esse movimento ocorrendo de forma sincrônica num mesmo estado, região ou país. Sua velocidade de reprodução está acima da maioria das atividades humanas, não respeitando fronteiras ou limites territoriais, alimentando-se, quase sem escrúpulos, dos mais variados setores do conhecimento humano, especialmente daqueles ligados aos avanços tecnológicos e informacionais.

Rodrigues $(1997,1996)$, propõe uma sistematização das dimensões espacial e territorial do turismo a partir de três elementos organizadores: os pólos compostos pelas áreas emissoras de turistas, os pólos definidos pelas áreas receptoras e as linhas de ligação desses pólos, por onde circulam os turistas e as informações É nas áreas receptoras que podemos identificar o território do turismo ou o lugar turístico por excelência.

\footnotetext{
* Professor do Curso de Turismo do Centro Universitário Plínio Leite, Niterói (RJ), aluno do Mestrado em Geografia da UFF.
} 
É no lugar turístico que o fenômeno se materializa e sobrepõe suas formas fixas: atrativos turísticos, equipamentos e serviços turísticos (meios de hospedagem, serviços de alimentação, agentes receptivos, guias de turismo, locais e instalações para entretenimentos, etc.) e infra-estrutura de apoio (serviços de comunicações, transportes, segurança, etc.). É o locus da produção e do consumo do produto turístico ${ }^{1}$, que, pelas peculiaridades dessa atividade, em alguns momentos ocorrem simultaneamente.

O lugar turístico reúne o espaço e o território. Enquanto prática socio-espacial, o turismo vai se apropriando de determinados espaços, transformando-os e, a partir disso, produzindo territórios e territorialidades flexíveis e descontínuas (SOUZA, 1995), e "turistificando" os lugares (NICOLÀS,1996; KNAFOU,1996). No dizer de Nicolàs:

(...) el turismo crea, transforma (sic), e inclusive (sic) valoriza diferencialmente espacios que podian (sic) no tener 'valor' en el contexto de la lógica de producción: de repente la tierra de pastizal se puede transformar en parque de acampar, o la casa semi-derruida del abuelo fallecido en casa de hospedes (NICOLAS, 1996:49).

Knafou (1996), em suas análises sobre as relações entre turismo e território, também nos lembra que os turistas estão na origem do fenômeno, e que são eles que definem, escolhem os lugares turísticos. Sua proposta é que não devemos perder de vista que o sujeito do fenômeno, responsável pela sua existência, é o homem, na forma do turista. Pessoalmente, entendemos ser necessário ampliarmos esse conceito, incluindo, também como sujeito do fenômeno, a população das áreas receptoras.

Aquele autor nos sugere a possibilidade de três tipos de relações entre turismo e território: a) pode existir território sem turismo; b) pode existir um turismo sem território; c) podem, enfim, existir territórios turísticos, esses últimos entendidos como "territórios inventados e produzidos pelos turistas, mais ou menos retomados pelos operadores turísticos e pelos planejadores" (KNAFOU,1996: 72-3). Nesses últimos é que presenciamos conflitos de territorialidades entre os turistas - nômades - e os anfitriões - sedentários:

(...) há diferentes tipos de territorialidades que se confrontam nos lugares turísticos: a territorialidade sedentária dos que aí vivem freqüentemente, e a territorialidade nômade dos que só passam, mas que não têm menos necessidade de se apropriar, mesmo fugidiamente, dos territórios que freqüentam (p.64).

Para Falcão, "o turismo, qualificado como uma nova modalidade de consumo de massa, desenvolve-se no âmbito da emergente economia das trocas invisíveis em

\footnotetext{
${ }^{1}$ Aqui produto turístico é entendido como a soma dos atrativos turísticos, dos equipamentos e serviços turísticos e da infra-estrutura de apoio e de todas as suas interações e interrelações, conforme proposto por Boullón (1990) e Beni (1998).
} 
escala nacional e internacional. Esta modalidade se expande com a produção de bens (infra-estrutura, construções, alimentos e produtos diversos) e serviços (transportes, hospedagem, alimentação, etc.), que se integram para o consumo final. Esse conjunto de bens e serviços oferece ao mercado de consumo as 'condições de acessibilidade' a determinado lugar. O espaço, na dimensão do lugar, assume caráter de objeto de consumo e, como tal, é (re)produzido e comercializado" (FALCÃO, 1996:65). No nosso ponto de vista, é o território acrescido de um certo valor (simbólico) e de infra-estruturas territorializadas (meios de hospedagem, parques temáticos, aeroportos, etc.), que se transforma em produto e como tal, é vendido e consumido.

Por outro lado, entendemos o turismo como um fenômeno complexo, composto por um elenco relativamente grande de componentes que se relacionam e interrelacionam constante e simultaneamente, dentro de uma lógica que inclui muitas incertezas e casualidades.

Enquanto fenômeno sociocultural característico das sociedades pós-revolução industrial, o turismo tem fortes imbricações espaciais, que se manifestam de diversas maneiras e em diversos pontos do espaço, formando uma rede mundial composta de pontos de emissão, pontos de recepção e raios de fluxos materiais e invisíveis. Nessa rede, os pontos de recepção são classificados pelos mais diferentes nomes: centros turísticos, locais turísticos, regiões turísticas, áreas receptoras, etc.

Propomos sintetizá-los todos na categoria de lugar turístico, por entendermos que é na escala local que o fenômeno turístico se manifesta territorialmente, estabelecendo-se com toda a materialidade das suas relações e interações. Entender a sua organização e o seu ordenamento territorial passa obrigatoriamente pela compreensão do lugar turístico.

\section{Mas o que entendemos por lugar e por lugar turístico?}

\section{A categoria do Lugar na geografia}

A categoria do lugar, assim como outras categorias utilizadas freqüentemente pela geografia, apresenta diversas interpretações (SANTOS,1996), o que gera dificuldades no seu uso. Muitas vezes vemos o lugar ganhando o sentido de local, noutras de localidade. Dentre os diversos estudos da geografia humana, Yi-Fu Tuan é um dos autores que busca a compreensão da territorialidade humana e sua ligação com o lugar de maneira mais ampla. Para ele o geógrafo humano deve cuidar da tarefa de explicar como um "mero espaço se torna um lugar intensamente humano" (TUAN, 1985:149). Para tal empreitada, deve lançar mão de fatores como a "natureza da experiência, a qualidade da ligação emocional aos objetos físicos, as funções dos conceitos e símbolos na criação da identidade do lugar" (p.150).

Tuan entende que cada pausa ou parada nos movimentos humanos termina definindo uma localização, um lugar. Para ele, esses lugares podem ter grandes variações de tamanho, indo desde o pequeno lugar que pode ser conhecido pela experiência direta, 
até o estado-nação, que "pode ser transformada em lugar - uma localização de lealdade apaixonada - através do meio simbólico da arte, da educação e da política" (p.149).

Anthony Giddens no seu trabalho As Consequiências da Modernidade, nos fala do deslocamento do espaço do lugar provocado pela modernidade. Reportando-se a textos seus anteriores, o autor reafirma seu conceito de lugar enquanto "cenário físico da atividade social" (GIDDENS, 1991:26-7), mas vai além disso, acrescentando a separação do espaço do tempo, fator que irá estimular o surgimento de relações "entre outros ausentes, localmente distantes de qualquer situação dada ou interação face a face" (p.27), tornando o lugar cada vez mais fantasmagórico. As relações sociais são retiradas dos contextos locais e reordenadas a partir de grandes distâncias tempo-espaciais, através do que Giddens chama de "mecanismos de desencaixe" (p.29 e 59).

Soja (1993), analisando as propostas de Giddens em The Constituition of Society (1984), observa que aquele autor utiliza, algumas vezes, o termo local para falar do lugar. Para ele, o local é visto como "uma região limitada que concentra a ação e reúne, na vida social, tanto o singular e particular quanto o geral e nomotético" (SOJA, 1993:181). É no local que ocorrem as interações sociais entre os atores; interações essas que vão especificar as suas contextualidades .

Para Soja, entretanto, Giddens não reconhece que o fato do local concentrar as interações sociais, gera um contexto mais abrangente, o qual ele descreve como "a nodalidade da vida social, o acúmulo ou aglomeração de atividades em torno de centros ou nós geográficos identificáveis" (p.182), e que permite pressupor a ocorrência de relações sociais e de poder entre centros e periferias.

Avançando nos seus comentários, Soja apresenta uma definição para localidades, como sendo "tipos particulares de locais permanentes, social e espacialmente estabilizados através do estabelecimento aglomerado de sítios de atividades primária (sic) e do estabelecimento de comunidades territoriais afins. Como todos os locais, elas são estruturações espaço-temporais provenientes da combinação da ação humana e do impacto condicionador das condições espaço-temporais preexistentes" (SOJA, 1993:185).

No seu trabalho mais recente - A Sociedade em Rede - Manuel Castells argumenta que mesmo diante de uma tendência para uma hegemonia dos espaços de fluxos, o lugar continua sendo uma categoria importante para a compreensão espacial das sociedades atuais, já que "a grande maioria das pessoas [...] vive em lugares e, portanto, percebe seu espaço com base no lugar" (CASTELLS, 1999:447). O autor concebe o lugar como sendo "um local cuja forma, função e significado são independentes dentro das fronteiras da contiguidade física" (p.447), cujas características marcam a vida dos seus habitantes e, podem ou não, contribuir para a formação de uma comunidade.

Merece ressaltar a posição de Castells quanto ao lugar não ser obrigatoriamente uma comunidade. Os habitantes do lugar podem, de acordo com o autor, não se amarem ou se relacionarem, mas têm suas vidas marcadas pelas características do lugar. Para ele o lugar não necessariamente exprime e revela interações sociais e riqueza 
espacial. "É exatamente porque suas qualidades físicas/simbólicas os tornam diferentes que eles são lugares" (p.449).

Ainda na sua análise dialética entre os espaços de fluxos e os espaços de lugares, Castells prevê uma tendência para a hegemonia dos "espaços de fluxos aistóricos em rede" que objetivam impor aos lugares a sua lógica, tornando-os segmentados e espalhados e "menos capazes de compartilhar códigos culturais" (p.452). Para o autor, o poder na sociedade atual está situado nos espaços de fluxos, o que altera fundamentalmente a dinâmica dos lugares, tornando a experiência vivida pela pessoas destacada do poder e o significado separado do conhecimento, gerando "uma esquizofrenia estrutural entre duas lógicas espaciais" (p.451) - dos fluxos e dos lugares - que pode vir a romper os canais de comunicação dessa mesma sociedade.

Carlos, visualiza um processo de redefinição do lugar enquanto dimensão práticosensível dentro do momento histórico atual de globalização. Para a autora, a globalização "materializa-se concretamente no lugar [...] no lugar se vive, se realiza o cotidiano, e é aí que ganha expressão o mundial" (CARLOS, 1996a:15). O global e o local coexistem e o primeiro redefine o segundo sem anular suas particularidades. $\mathrm{O}$ lugar teria em si a possibilidade de permitir o entendimento do processo atual de produção, consumo e apropriação do espaço, através "da perspectiva de se pensar seu processo de mundialização" (p.15).

Concordando com Milton Santos, quando este autor coloca que o lugar pode ser definido a partir das densidades técnica, informacional, comunicativa e normativa, a autora propõe acrescentar-se "a dimensão do tempo em cada lugar que poderia ser visto através do evento no presente e no passado" (p.20).

Por sua vez, Milton Santos conclui seu trabalho A Natureza do Espaço afirmando o lugar como o espaço irredutível, banal, por reunir logicamente o homem, as empresas, as instituições, as formas sociais e jurídicas e as formas geográficas, que unidos formam o cotidiano imediato. Para o autor, enquanto o global "desterritorializa", o local "reterritorializa", por ser composto por um conjunto de objetos contíguos e interagentes. (SANTOS,1996)

Para aquele autor, nosso momento histórico atual traz a categoria do lugar para o centro das discussões. Entretanto, ela precisa ser revista e atualizada para, a partir de novos significados, dar conta da complexidade do mundo globalizado atual. Segundo ele, uma das possibilidades é entender o lugar a partir do cotidiano, visto este como uma categoria da existência passível de um tratamento geográfico, que permita apreender o lugar enquanto expressão do local e do global.

O lugar é o quadro de uma referência pragmática ao mundo, do qual lhe vêm solicitações e ordens precisas de ações condicionadas, mas é também o teatro insubstituível das paixões humanas, responsáveis, através da ação comunicativa, pelas mais diversas manifestações da espontaneidade e da criatividade (SANTOS, 1996:258).

No lugar, temos superpostos os tempos das escalas superiores e os tempos internos, da coexistência, onde tudo se funde. Nele, os objetos, as ações, a técnica e o tempo se concretizam. É no lugar que as técnicas ganham realidade histórica, e onde cada obje- 
to e ação têm o seu valor real estabelecido pela sua posição dentro do funcionamento do conjunto.

No interior das redes globais, o lugar se mostra como um dos níveis de análise que permitem apreender os seus movimentos contraditórios. É nele que "fragmentos da rede ganham uma dimensão única e socialmente concreta, graças à ocorrência, na contiguidade, de fenômenos sociais agregados, baseados num acontecer solidário, que é fruto da diversidade e num acontecer repetitivo, que não exclui a surpresa" (p.215).

Os lugares podem, segundo Santos, ser definidos a partir de suas densidades técnica, informacional e comunicacional, as quais, num jogo de circularidade construtiva os caracterizam e os tornam especializados dentro de um contexto global. Numa luta constante cada lugar busca sua competitividade na diversidade e nas suas individualidades, realçando "suas virtudes por meio de seus símbolos herdados ou recentemente elaborados, de modo a utilizar a imagem do lugar como imã" (p.214).

O autor aponta ainda o lugar como locus de uma possível resistência à atual globalização e ao processo de verticalização dos lugares. Isso será possível, segundo ele, através do fortalecimento das horizontalidades entre os lugares e da reconstrução de "uma base de vida que amplie a coesão da sociedade civil, a serviço do interesse coletivo" (p.228). O autor propõe o desenvolvimento de uma solidariedade ativa, geradora de ações políticas locais que se anteponham às tendências meramente verticalizantes (p. 228-9).

Diante dessa possibilidade de entendermos melhor o processo atual de mundialização a partir do lugar, e reconhecendo no turismo um dos principais vetores desse processo, como podemos analisar o lugar turístico?

\section{O Lugar Turístico e o ordenamento territorial do fenômeno turístico}

Como dito anteriormente, podemos ver o turismo a partir de três formas distintas de incidência territorial: as áreas emissoras, as áreas receptoras e os corredores de deslocamentos. Segundo Rodrigues, é nessas três formas "que se produz o espaço turístico" (RODRIGUES, 1997:43).

Entendendo que esses três elementos estão descontínuos mas interligados no espaço, podemos aí estabelecer um território-rede (SOUZA, 1995) do turismo, onde as áreas emissoras e as áreas receptoras se apresentam como nós e os corredores de deslocamentos são os raios que os interligam permanente (rodovias, ferrovias) ou temporariamente (rotas aéreas, redes de comunicação). Os deslocamentos dos turistas estabelecem um sistema de interações entre lugares, firmas, instituições e indivíduos, o qual pode ser representado pelo que Raffestin (1980) classifica como um "sistema de malhas, nós e redes", ou pelo que Souza (1995) propõe como território descontínuo ou território-rede.

Sob a ótica do seu processo e da sua organização, o turismo estabelece uma rede de lugares (nós), localizados em pontos diferentes do espaço, mas que, por suas caracte- 
rísticas funcionais, mantêm entre si uma certa ligação de comando. Ou seja, existe uma supra-estrutura (organização) que mantém um nível de gerenciamento (por extensão, de poder) sobre esses lugares, interligando-os através de objetivos comuns. O lugar (nó) emissor precisa do lugar (nó) receptor para satisfazer as demandas dos turistas e, para informá-los e transportá-los, estabelece linhas que unem esses lugares (nós), formando uma rede complexa.

Queremos aqui nos deter nos nós compostos pelas áreas receptoras, onde o fenômeno turístico se manifesta na íntegra e ganha, no dizer de Santos (1996), sua "realidade histórica".

A nomenclatura dada a essas áreas varia de autor para autor, indo de centro turístico a núcleo, área ou local turístico. O arquiteto argentino Roberto Boullón, um dos fundadores do CICATUR - Centro de Capacitação Turística da $\mathrm{OEA}^{2}$, desenvolveu uma teoria para o estudo do espaço turístico, onde esse espaço é hierarquizado (sob o ponto de vista de escala) na seguinte ordem: zona (unidade maior), área, complexo, centro, unidade, núcleo, conjunto (unidade menor) e corredor turístico (BOULLÓN,1985).

No nosso entender, aquele autor propõe um método empírico para se observar e analisar o espaço produzido pelo turismo e, a partir de procedimentos sistemáticos, estabelecer o seu ordenamento físico. Para ele, centro turístico é todo aglomerado urbano que "conta em seu próprio território ou dentro de seu raio de influência com atrativos turísticos de tipo e hierarquia suficientes para motivar uma viagem turística" (BOULLÓN, 1985:69-70).

São poucos os trabalhos científicos desenvolvidos no sentido de buscar-se o conhecimento da lógica do ordenamento territorial das áreas receptoras de fluxos turísticos. Em sua grande maioria, são abordagens teórico-críticas que buscam destacar os aspectos negativos dos impactos da atividade turística, colocando o fenômeno como elemento destruidor das identidades dos lugares.

Carlos (1996a; 1996b), desenvolve um estudo em que propõe ver o turismo apenas como um elemento produtor de não-lugares. No seu trabalho $O$ Lugar no/do Mundo (1996a), no capítulo onde aborda a questão da produção do não-lugar, apresenta a "indústria do turismo" como grande responsável por essa produção:

A indústria do turismo transforma tudo o que toca em artificial, cria um mundo fictício e mistificado de lazer, ilusório onde o espaço se transforma em cenário, 'espetáculo' para uma multidão amorfa [...]. Aqui o sujeito se entrega às manifestações desfrutando a própria alienação. Esses dois processos apontam para

\footnotetext{
${ }^{2}$ Instituto ligado à OEA sediado na cidade do México que, durante o período de 1974 a 1984, funcionou como centro de referência para os trabalhos de planificação turística na América Latina. Foi responsável pela publicação de extensa bibliografia contendo propostas metodológicas para o planejamento do turismo, a qual ainda hoje é referência para os profissionais da área.
} 
$o$ fato de que ao vender-se o espaço, produz-se a não-identidade $e$, com isso, $o$ não-lugar (CARLOS, 1996a:109)

Avançando nessa linha de pensamento, a autora nos coloca que o "espaço produzido pela indústria do turismo perde o sentido, é o presente sem espessura, quer dizer, sem história, sem identidade, neste sentido é o espaço do vazio. Ausência. Não-lugares" (p.116).

Rodrigues (1997), também aborda a questão do lugar e do não-lugar produzido pelo turismo. Para essa autora, "o lugar, como categoria filosófica, não trata de uma construção objetiva, mas de algo que existe do ponto de vista do sujeito que o experencia [...] é o referencial da experiência vivida, pleno de significado" (RODRIGUES, 1997:32). Seguindo essa linha de pensamento, para ela os resorts são a melhor expressão de não-lugares, uma vez tratarem-se de empreendimentos implantados em áreas exóticas, de tal forma a dar ao turista total segurança. "Produz-se no espaço global um lugar, que nega o local, sendo, portanto, um não-lugar" (p.31-2) .

Contrapondo-se a essa tendência, Maria Tereza D. P. Luchiari, no seu trabalho Urbanização Turística: Um novo nexo entre o lugar e o mundo, propõe uma análise mais complexa da atividade turística, de modo a vê-la como "um dos vetores mais importantes para associar o mundo ao lugar, o global ao local" (LUCHIARI, 1998:16). Para aquela autora, as discussões sobre a questão global-local ou local-global avançaram e já não se coloca com tanta certeza que a globalização implica no fim do local, na destruição das diferenças e peculiaridades locais:

Tanto as peculiaridades locais, os localismos, os regionalismos emergiram deste global, quanto a própria globalização econômica passou a valorizar as diferenciações dos lugares, fazendo dessa diferenciação um atrativo para o capital (LUCHIARI, 1998:16).

Focando seus estudos na questão da urbanização das cidades turísticas, Luchiari apresenta alguns elementos que, no nosso modo de ver, são pertinentes para a compreensão da lógica territorial dos lugares turísticos. Logo de início ela nos propõe entender o lugar (para ela o mesmo que local) como "o resultado de um feixe de relações que soma as particularidades (políticas, econômicas, sociais, culturais, ambientais...) às demandas do global que o atravessa". Para ela, o espaço enquanto abstração, se realiza e se concretiza através das práticas sociais que "constróem a identidade vivida cotidianamente nos lugares" (p.16).

\footnotetext{
${ }^{3}$ Rodrigues nos cita como exemplo desses não-lugares, o resort Hyatt Regency Waikaloa, localizado no Havaí, projetado pelo arquiteto Christopher Hommeter, "o mago dos sofisticados resorts da atualidade" (p.31) e os empreendimentos das megacadeias hoteleiras mundiais, que são detalhadamente iguais, em qualquer local do mundo.
} 
A seguir, Luchiari nos leva a ver o lugar como um elemento dinâmico, onde podemos presenciar o movimento dialético (ou dialógico!) constante existente entre o lugar e o mundo, resultante dos processos da sociedade atual. Nesse movimento as cidades turísticas se organizam não para a produção, mas para o consumo de bens, serviços e paisagens. O que para alguns autores é tido como impacto negativo do turismo (a destruição dos lugares), a autora prefere entender como um processo de construção de

(...) novas formas contemporâneas de espacialização social, por meio das quais estamos construindo novas formas de sociabilidade, mais híbridas e mais flexíveis.(...) estabelece-se uma relação entre antigas paisagens $e$ velhos usos $e$ novas formas e funções, impulsionando a relação do lugar com o mundo, que o atravessa com novos costumes, hábitos, maneiras de falar, mercadorias, modo de agir (...) Assim também, a identidade do lugar é constantemente recriada, produzindo um espaço social híbrido, onde o velho e o novo fundem-se dando lugar a uma nova organização socio-espacial (LUCHIARI, 1998:17).

Nessa linha de raciocínio, a autora nos leva a reavaliar os modelos de evolução dos lugares turísticos difundidos nos anos 80 , onde esses seriam descobertos pelo turismo mais elitizado, a seguir saturados e destruídos pelo turismo de massa e, finalmente, abandonados e substituídos por outros lugares recém descobertos.

Nicolàs, por sua vez, nos lembra que o uso do espaço pelo turismo não segue as mesmas leis das atividades de produção e reprodução dos setores econômicos tradicionais:

El espacio-consumido pero no forzosamente destruído, implica que la producción turística no obedece a las leyes de la producción económica tradicional; el espacio turístico se crea y recrea como valor de uso (y también de cambio) sin que su destrucción sea obligada, aunque a veces ocurra (NICOLÀS, 1996:44).

Também Remy Knafou nos propõe rever essa linha ideológica que encara o turismo como vetor destruidor, quase que antropofágico, devorador daquilo que seria o seu próprio recurso, a paisagem. Para aquele autor a paisagem transforma-se e não se destrói e, "o que desagrada a um turista pode muito bem convir a outro, sobretudo se ele descobre o sítio em seu estado atual, sem tê-lo conhecido pouco ou não transformado, o que lhe impede de ter uma percepção nostálgica" (KNAFOV, 1996:67).

Retornando a Luchiari, podemos ver que também para ela, a paisagem é uma construção social e, como tal, está em constante transformação: "Se admitimos que a paisagem é uma representação [a partir do olhar do observador] e não um dado da natureza, não podemos concordar que ela seja um recurso não renovável" (p.23). 
Ou seja, o turismo, para acontecer, apropria-se dos lugares, consome suas paisagens, promove relações e interações, temporárias e permanentes, estabelecendo articulações lugar-mundo, através da inserção dos lugares turísticos numa rede ampla e complexa.

\section{Os lugares turísticos atuais}

O turismo atual, segundo as estatísticas da Organização Mundial de Turismo OMT e de outros organismos internacionais e diversos estudos recentes, passa por um processo de reestruturação, gerado por uma nova forma de vida que a sociedade atual vem buscando, o que vem fazendo surgir o chamado turismo alternativo (NICOLÀS,1996). Trata-se de um modelo que propõe viagens mais curtas, mais individualizadas (pequenos grupos), voltados para o contato com a natureza (turismo ecológico) e com as comunidades locais (turismo rural e cultural).

O turismo de massa continua respondendo, quantitativamente, pela maioria dos fluxos de demanda, mas assiste-se a uma tendência crescente de segmentação dessa demanda, com o surgimento de um turista mais consciente, mais exigente, menos passivo e mais preocupado com a qualidade das suas experiências durante a viagem. Ainda segundo a OMT, enquanto o turismo de massa cresce a uma taxa anual média de 5\%, o turismo segmentado (alternativo) vem mantendo uma taxa anual de crescimento acima de $10 \%$ nos últimos anos.

Esse novo perfil da demanda turística está exigindo dos operadores turísticos e dos gestores das áreas receptoras a criação de produtos especializados que permitam ao turista uma vivência no lugar visitado mais ativa, onde sejam possíveis contatos diretos, sem barreiras, com os habitantes locais e o estabelecimento de relações pessoais entre eles. O turista deixa de ser o invasor, o intruso, o estranho (KNAFOU, 1996) e passa a ser o outro para o habitante do lugar, enquanto esse passa a ser o outro para o turista, ambos com formações e informações culturais distintas e interessados na troca mútua de experiências.

É o revigoramento do conceito do turismo enquanto momento de encontro de alteridades, onde é possível a troca de experiências socioculturais e do enriquecimento pessoal, tanto do turista como do anfitrião. Ou seja, o turismo acontecendo enquanto fenômeno sociocultural e não apenas como atividade econômica.

Nesse caso, o turismo não produz um não-lugar como nos coloca Carlos (1996), mas sim permite a construção de um lugar onde a marca principal está na troca de experiências pessoais, entre o seu habitante e o turista. O lugar turístico é, precisamente, o lugar do encontro do anfitrião com o turista, lugar onde seres humanos diferentes podem manter uma relação face-a-face e estabelecer uma troca de conhecimento, de sensações e de desejos.

Não estamos aqui negando a existência dos não-lugares, produzidos pelo turismo, apontados por Rodrigues (1997) e Carlos (1996). Eles existem, ainda são hegemôni- 
cos no mercado turístico mundial e continuam se reproduzindo como uma das formas mais ativas da mundialização do capital financeiro.

Diariamente vemos surgir novos centros turísticos artificiais, voltados a atender essa demanda de turistas passivos, interessados em uma experiência de evasão (ou seria de alienação?) dos seus cotidianos, mas sem correr riscos ou ameaças. Turistas que não buscam o contato com o outro, mas que, pelo contrário, querem se passar por anônimos, comprar souvenirs, assistir espetáculos culturais artificiais, tirar fotos, filmar as paisagens com suas câmaras modernas e retornar para seus lugares, satisfeitos por terem consumido tudo o que the foi oferecido.

Entretanto, existe um outro tipo de turista que já não se satisfaz com o que Knafou (1996) classifica de turismo fora do solo. São os turistas que já não aceitam ficar dentro de um ônibus hermeticamente fechado, climatizado, vendo e fotografando a paisagem pela janela. É esse turista mais consciente e ávido pelo contato face-a-face com o habitante do lugar visitado, que possibilita falarmos da produção do lugar turístico. Entretanto, esse lugar turístico só é passível de existência a partir do momento que entendamos o turismo enquanto fenômeno sociocultural complexo, no qual seus agentes e componentes existem num jogo constante de interações, onde cada um é ao mesmo tempo causa e efeito no circulo do processo.

Assim, não apenas o turista é sujeito. No momento do encontro com o habitante do lugar, ambos são sujeitos no processo de interação consciente com o outro. Não há aqui a relação positivista reducionista sujeito-objeto; pelo contrário, a relação é dialógica e apresenta uma circularidade construtiva (MORIN,1999), carregada de uma grande dose de ordem-desordem e de incertezas.

O lugar turístico que aqui conceitualmente propomos é o território onde o turismo se realiza, e onde há a ocorrência de interações e inter-relações temporárias entre o anfitrião e o turista, aos quais irão permitir um contato direto, sem barreiras (físicas ou simbólicas) entre eles e o reconhecimento da existência do outro, recíproca e simultaneamente.

Para o turista essa experiência irá trazer um crescimento pessoal e a satisfação das expectativas, sonhos e ansiedades que o levaram a estabelecer sua viagem. A viagem torna-se um momento de aprendizado, de crescimento. Para o habitante, o anfitrião, a experiência irá propiciar, além do seu crescimento pessoal interior, a consolidação da sua identidade com o seu lugar e a consciência de todas as possibilidades do seu cotidiano. A interação com o turista, nômade, torna-se um fator de fortalecimento e de recriação da sua noção de pertencimento ao lugar.

Para o turista o lugar turístico é o espaço e o momento efêmero de uma experiência, real e direta, de descoberta de si e do outro. Não há aqui a idéia do espaço de lazer dissociado do espaço de vida, como proposto por Carlos (1996a). Pelo contrário, no lugar turístico, ambos, o espaço de lazer e de vida, ocorrem simultaneamente para o turista. Para o habitante é o lugar permanente onde estão suas experiências vividas; é a sua dimensão de vida, definida a partir da suas relações interativas com o outro - o 
turista. Desse modo, o lugar turístico passa a existir enquanto um espaço relacional turista-habitante, sendo efêmero para o primeiro e permanente para o segundo.

Parafraseando Milton Santos (1996), vemos o lugar turístico como o lugar onde os fragmentos das redes mostram sua dimensão social concreta, pois é nele que o fenômeno turístico ocorre, solidária e repetitivamente, fruto da diversidade e das incertezas das relações entre a população local residente e os turistas.

\section{OS LUGARES TURÍSTICOS: TERRITÓRIOS DO FENÔMENO TURÍSTICO}

Resumo: Neste artigo abordamos o turismo enquanto fenômeno típico da sociedade capitalista atual, fruto de práticas socioespaciais, as quais geram territórios e territorialidades e "turistificam" lugares. Analisamos as áreas receptoras, locus de produção e consumo do produto turístico, enquanto "nós" de uma rede complexa, visualizados como lugares turísticos. Diante da tendência atual de segmentação dos fluxos de demanda, e do aumento do nível de exigência dos turistas, propomos entender o lugar turístico enquanto espaço relacional habitante-turista, local de ocorrência de interações e inter-relações temporárias entre o anfitrião e o visitante, as quais possibilitam o reconhecimento da existência do outro, recíproca e simultaneamente.

Palavras-chave: turismo, lugar turístico, lugar, território

\section{THE TOURISTIC PLACES: TOURISTIC PHENOMENON'S TERRITORIES}

Summary: The subject of the article is tourism as a tipical phenomenon of the present capitalism society: result of social-spacial activities which generates territories, territoriality and places which became touristic. We analyse the receiver areas, "locus" of production and consumption of the touristic product as "knots" of a complex net visualized as touristic places. Facing the present tendency to segment the demand and the increasing level of tourist exigencies, we propose to understand the touristic places as a relation between tourist and local inhabitants, places of interactions and relations between both, in order to recognize the other, reciprocally and simultaneouly

Keywords: tourism, touristic places, places, territories

\section{BIBLIOGRAFIA}

BENI, M. (1998): Análise Estrutural do Turismo. São Paulo: SENAC. BOULLÓN, R. C. (1990): Planificación del espacio turistico. México: Trillas. CARLOS, A. F. A. (1996a): O Lugar no/do Mundo. São Paulo: HUCITEC.

(1996b): O turismo e a produção do não-lugar. In: Eduardo Yasigi (org.).Turismo Espaço, paisagem e cultura. São Paulo: HUCITEC,.

CASTELLS, M. (1999): A Sociedade em Rede. (A era da informação: economia, sociedade e cultura, v.1). São Paulo: Paz e Terra.

GIDDENS, A. (1991): As Conseqüências da Modernidade. São Paulo: Martins Fontes Editora.

FALCÃO, J. A. G (1996): O turismo internacional e os mecanismos de circulação e transferência de renda. In: Eduardo Yasigi (org.) Turismo. Espaço, paisagem e cultura. São Paulo: HUCITEC, 1996. 
KNAFOU, R. (1996): Turismo e Território. Por uma abordagem científica do turismo. In: Adyr A. B. Rodrigues (org.). Turismo e Geografia. Reflexões teóricas e enfoques regionais. São Paulo: HUCITEC.

LUCHIARI, M. T. D.P. (1998): Urbanização Turística: um novo nexo entre o Lugar e o mundo. In: Luiz Cruz Lima (org.). Da Cidade ao Campo: A Diversidade do saber-fazer turístico. Fortaleza-CE: UECE.

MOESCH, N. M. (1998): Turismo: virtudes e pecados. In: Susana Gastal (org.). Turismo: 9 propostas para um saber-fazer. S/local: dos autores.

MORIN, E. (1999): Ciência com Consciência. Rio de Janeiro: Bertrand Brasil. (1996): Epistemologia da Complexidade In: Dora Fried Schnitman (org.) Novos Paradigmas, Cultura e Subjetividade .Porto Alegre: Artes Médicas.

NICOLÁS, D. H. (1996): Elementos para un análisis sociogeográfico del Turismo In Adyr A.B. Rodrigues (org.) Turismo e Geografia.Reflexões Teóricas e Enfoques Regionais. São Paulo: HUCITEC.

RAFFESTIN, C. (1993) [1980]: Por Uma Geografia do Poder. São Paulo, Ática. .(org.) 1996: Turismo e Geografia. Reflexões Teóricas e Enfoques regionais. São Paulo: Editora HUCITEC.

RODRIGUES, A. B. (1997): Turismo e Espaço. Rumo a um conhecimento transdisciplinar São Paulo: Editora HUCITEC.

(org): Turismo e Geografia. Reflexões Teóricas e Enfoques Regionais. São Paulo: Editora HUCITEC.

SANTOS, M. (1996): A Natureza do Espaço: técnica e tempo, razão e emoção. São Paulo: Editora HUCITEC.

SOJA, E. W. (1993) [1989]: Geografias pós-modernas: a reafirmação do espaço na teoria social. Rio de Janeiro: Jorge Zahar.

SOUZA, M. J. O (1995): Território: sobre espaço e poder, autonomia e desenvolvimento. In: Iná Elias de Castro et all (org.). Geografia: conceitos e temas. Rio de Janeiro: Bertrand Brasil.

TUAN, Y.F.(1985): Geografia Humanística. In: Antônio Christofoletti (org.) Perspectivas da Geografia. São Paulo: Difel. 